\title{
CULTURA DE DIATOMACEAS
}

\author{
*Ari Tomi Takahashi \\ * * Marie Imai \\ *** Marcio Rogério Grosskopf
}

As algas diatomaceas são amplamente utilizadas como alimento das larvas de peneideos nas fases de protozoea ou zoea, desta forma ocupa lugar preponderante na cadeia alimentar dos camarões, embora possa ser substitu ida por leveduras que se administrada de forma irregular, pode causar sérios transtornos no cultivo do crustaceo.

$\mathrm{Na}$ larvicultura de Penaeus paulensis e Penaeus brasiliensis no Centro de. Biologia Marinha, as diatomareas estão sendo obtidas em tanques ahertos sujeitos as variações climáticas e de salinidade, cuja água é bombeada diretamente do mar. sem nenhuma espécie de filtragem e, adicionada ureia $45 \%$, superfosfato e silicato de sódio.

Nesta nota prévia, procuramos divulgar que as diatomareas podem ser facilmente cultivadas em qualquer escala de modo simples e econômico, porque :s usa por princípio os fertilizantes usados na agricultura. dispensando outros artificios quaisquer.

Com a aeração contínua obtem-se em carca de 15 horas uma cultura substancial de diatomaceas dos seguintes gêneros: Chaetoceros spp., Skeletonema spp., Asterionella spp., Rhizosolenia spp., Thalassionema spp., bem como outraaceitáveis pela forma protozoea.

Das nossas observações, concluimos que pode-se cultivar em trmpo aberto. até usando luvas impermeáveis como tanques e uma arração persistente.

*Professor do Centro de Biologia Marinha - UFPr

**Estagiária do Centro de Biologia Marinha - UFPr

***Tecnologista do Centro de Biologia Marinha - UFPr

\section{SUMARY:}

The present note gives information on outdoor mass production of Diatom: Algae for feeding differents species of shrimp of the Genus Penaeus. 